HELMINTHOLOGIA, 54, 2: 105 - 112, 2017

\title{
Molecular characterization of Baylisascaris devosi Sprent, 1952 (Ascaridoidea, Nematoda) from Kamchatka sables
}

\author{
NINA A. TRANBENKOVA' ${ }^{1}$, SERGEI E. SPIRIDONOV ${ }^{2}$
}

${ }^{1}$ Kamchatka Branch of the Pacific Institute of Geography, Far Eastern Division of the Russian Academy of Sciences, 683000, Petropavlovsk-Kamchatskii, Partizanskaya str., 6, E-mail: helm@mail.ru; ${ }^{2}$ Severtsov Institute of Ecology and Evolution, Russian Academy of Sciences, 119071, Moscow, Leninskii pr., 33, E-mail: s_e_spiridonov@rambler.ru

\section{Article info}

Received October 6, 2016 Accepted March 17, 2017

\begin{abstract}
Summary
The nematodes of the genus Baylisascaris are common intestinal parasites of sables (Martes (M.) zibellina kamtschadalica Birula, 1916) on the entire territory of Kamchatka peninsula. Partial sequences of Cox I mitochondrial gene were used for molecular characterization of these nematodes, which confirmed the identification based on morphological data as B. devosi Sprent, 1952. Phylogenetic relationships of this Baylisascaris species were also inferred from the ITS rDNA and LSU rDNA sequences. SEM images were provided for taxonomically important morphological features.

Keywords: Ascaridids; CoxI mtDNA; ITS rDNA; LSU rDNA; nucleotide differences; SEM
\end{abstract}

\section{Introduction}

The studies on the parasites of Kamchatka sable (Martes (M.) zibellina kamtschadalica Birula, 1916) were started more than 80 years ago (Petrow, 1930). Then, the representatives of Ascaridoidea were found along with metastrongylid and dioctophymid nematodes. According to the contemporary taxonomical views and in concordance with the opinion of Wilkie (1930), these ascaridids were identified as Ascaris columnaris (Leidy, 1856). Sprent (1952) described new species of ascaridids from the fishers and martens as Ascaris devosi. Discovered ascaridids of sables were described in several monographs and papers covering parasites of Mustellidae of the USSR (Kontrimavichus, 1963, 1966; Kontrimavichus \& Skrjabina, 1963; Kozlov, 1977), where the same binomial, Ascaris columnaris, was used. At that time Sprent (1968) had established for the ascaridid parasites of predatory mammals and rodents a new genus Baylisascaris Sprent, 1968 with type species Baylisascaris transfuga (Rudolphi, 1819), where he had transferred 'Ascaris devosi'. Kontrimavichus (1969) accepted the new genus and proposed to consider as Ascaris columnaris (Leidy, 1856) only parasites of skunks, having agreed that ascaridids of mustelids are to be considered as Baylisascaris devosi Sprent, 1952. Though this opinion was supported by Mozgovoy \& Shakhmatova (1973), the specific binomial Ascaris columnaris was used in Russian literature for the ascaridids of sables during some time (Tranbenkova, 1987).

The genus Baylisascaris Sprent 1968 includes eleven valid species of intestinal parasites of mammals. Apart from Baylisascaris tasmaniensis Sprent, 1970 from marsupials (Sprent,1970) and Baylisascaris laevis (Leidy, 1856) from rodents (Sprent, 1968), all remaining species were found parasitizing carnivores: pandas (Xie et al., 2011), bears (Perez et al., 2016), kinkajou (Tokiwa et al., 2014), skunks, raccoons and various mustelids: badgers, fishers, sables, wolverines (Sprent, 1968). Sprent (1952) had demonstrated that $2^{\text {nd }}$ stage juveniles of $B$. devosi swallowed by mice moulted with the formation of 3rd stage juveniles and encapsulated in the muscles of these paratenic hosts. The predation by carnivores on paratenic hosts with encapsulated $B$. devosi juveniles resulted in the development of mature nematodes in the intestinal tract of a definitive host. The possibility of the direct invasion of a definitive host with mature eggs of $B$. devosi was also demonstrated (Sprent, 1953). 
Long term survey of Kamchatka sables conducted by the first author (N.A.T.) demonstrated the widespread infection with cestodes Taenia martis (Zeder, 1803) Freeman, 1956 and Mesocestoides lineatus (Goeze, 1782) Railliet, 1893 and nematodes: Capillaria putorii (Rudolphi, 1819), Travassos, 1915; Thominx aerophilus (Creplin, 1839) Skrjabin et Schikhobalova, 1954; Trichinella spiralis (Owen, 1835), Soboliphyme baturini Petrow, 1930; Crenosoma petrowi Morosow, 1939; Crenosoma vulpis (Dujardin, 1874) Railliet, 1915; Filaroides martis Werner, 1782 and Baylisascaris devosi Sprent, 1952. Clear biogeographical pattern in B. devosi prevalence in the area was revealed: it is increasing from the South-West of the peninsula toward its central and north-eastern (mainland) part of Kamchatskii Krai (administrative region). While the prevalence of the $B$. devosi invasion in Ust-Bolsheretsky $\left(52^{\circ}\right.$ $48^{\prime} \mathrm{N}, 156^{\circ} 17^{\prime} \mathrm{E}$ ) and Sobolevsky administrative districts (54 $17^{\prime}$ $\mathrm{N}, 155^{\circ} 57^{\prime} \mathrm{E}$ ) was on the level of $1-2 \%$ of the sables examined, it reached approximately $12-13 \%$ in Ust-Kamchatsky administrative district, $27 \%$ in Milkovsky district (54 $\left.40^{\circ} \mathrm{N}, 158^{\circ} 38^{\prime} \mathrm{E}\right)$ and $29 \%$ in Karaginsky district $\left(59^{\circ} 55^{\prime} \mathrm{N}, 162^{\circ} 07^{\prime} \mathrm{E}\right)$. The intensity of infection also complies with the same geographical patterns: when in the majority of administrative districts it ranged between 1 - 12 specimens per infected host, the intensity values amounted to 55 specimens in some sables of Milkovsky district. Only single $B$. devosi specimens were observed in sables from Olutorsky and Penginsky administrative districts (located outside of Kamchatka peninsula on the Siberian mainland).

Morphological differences between recognized Baylisascaris species of predaceous mammals are not so clear-cut, but accumulation of sequence data for ascaridids provides a possibility to elucidate unresolved problems of the genus taxonomy. Molecular data are available in the NCBI GenBank for several species of the genus Baylisascaris. For $B$. devosi from Canadian wolverines, the only available sequences were that of Coxl mtDNA. The aim of this study was to provide morphological and molecular data for Baylisascaris nematodes of Kamchatka sables, to confirm their morphology-based identification and bring new sequence data for phylogenetic analysis of the genus.

\section{Material and Methods}

The sables $M$. zibellina were obtained from hunters throughout the Kamchatka Peninsula. Frozen animals found in traps were hunter-skinned after removing from traps and frozen carcasses (37 - 116 carcasses were obtained from each administrative district) were sent to the Kamchatka Branch of the Pacific Institute of Geography, Far Eastern Division of the Russian Academy of Sciences for examination (temperature of transportation was always below $0^{\circ} \mathrm{C}$ ). After thawing, the sable carcasses were dissected and the nematodes were collected from the gastro-intestinal tract under low magnifications of dissecting microscope. For the morphological examination of an apical view, anterior body ends 2 $-4 \mathrm{~mm}$ long of several specimens were cut off and mounted onto temporary slides in glycerin. The shape of denticles of the edge of lips was examined under a compound light microscope (magnifications $\times 200-x 400$ ). The values of mean $\pm S D$ (range) were obtained for taxonomically important measurements.

The Baylisascaris devosi specimens originating from two localities on the Kamchatka Peninsula were used for the study, viz. Ust-Kamchatsky and Milkovsky administrative regions. One adult female and one adult male nematodes from each locality were selected for the study under a scanning electron microscope (i.e. totally two males and two females). Anterior and posterior ends of nematodes were dehydrated through a graded ethanol series and acetone and then dried to a critical point. Specimens were coated with gold/palladium and examined with a scanning electron microscope JSM-6380LA (JEOL, Tokyo, Japan).

For DNA extraction, the nematode specimens fixed in $70 \%$ ethanol were rehydrated overnight in autoclaved water. About $2-3 \mathrm{~mm}$ long fragments of a gonadal tube were excised from the nematode specimens used for the examination under a scanning electron microscope. DNA extraction was conducted according to the approach of Holterman et al. (2006). The worm-lysis solution (950 $\mu \mathrm{l}$ of mixture of $2 \mathrm{ml}$ of $1 \mathrm{M} \mathrm{NaCl}, 2 \mathrm{ml}$ of $1 \mathrm{M} \mathrm{Tris}-\mathrm{HCl}$, pH 8 plus 5.5 $\mathrm{ml}$ of deionized water plus $10 \mu \mathrm{l}$ of mercaptoethanol and $40 \mu \mathrm{l}$ of proteinase $\mathrm{K}, 20 \mathrm{mg} / \mathrm{ml}$ ) was prepared immediately before DNA extraction. Gonadal tissue was transferred to $25 \mu$ l of sterile water and after addition of $25 \mu$ l of worm-lysis solution the tube was incubated at $65^{\circ} \mathrm{C}$ for $90 \mathrm{~min}$. The tubes containing the homogenate were then incubated at $99^{\circ} \mathrm{C}$ for 5 min to deactivate proteinase $\mathrm{K}$ and $0.8-1.2 \mu$ l of homogenate was used as PCR template.

PCR reactions were performed using Encyclo Plus PCR kit (Evrogen $尺$, Moscow, Russia) according to the manufacturer's manual. Primer pairs HCO2198 (5'- TAA ACT TCA GGG TGA CCA AAA AAT CA -3') and LC01490 (5'- TAAACT TCA GGG TGA CCAAAA AAT CA -3') were used to obtain partial sequence of mitochondrial Coxl gene (Folmer et al., 1993). PCR cycling parameters included primary denaturation at $94{ }^{\circ} \mathrm{C}$ for 5 min followed by 34 cycles $94{ }^{\circ} \mathrm{C}$ for $45 \mathrm{~s}, 41^{\circ} \mathrm{C}$ for $30 \mathrm{~s}$ and $72{ }^{\circ} \mathrm{C}$ for $1 \mathrm{~min}$, followed by post-amplification extension at $72^{\circ} \mathrm{C}$ for $3 \mathrm{~min}$.

Another pair of primers JB3_F (5'- TTT TTT GGG CAT CCT GAG GTT TAT - 3') and JB7GED_R (5'- ATC AGG ATA ATC CAA ATA YTT WCG WGG - 3') was used to amplify 650 bp long 3' portion of the same Coxl gene of mtDNA (Bowles et al., 1992; Derycke et al., 2010). PCR cycling parameters included primary denaturation at $95^{\circ} \mathrm{C}$ for 5 min followed by 35 cycles of $94{ }^{\circ} \mathrm{C}$ for $45 \mathrm{~s}, 56{ }^{\circ} \mathrm{C}$ for $60 \mathrm{~s}$ and $72^{\circ} \mathrm{C}$ for $70 \mathrm{~s}$.

A pair of primers LSU391 (5'- AGC GGA GGA AAA GAA ACT AA - 3') and LSU501 (5'TCG GAA GGA ACC AGC TAC TA- 3') were used to amplify a $1100 \mathrm{bp}$ long sequence of D2D3 expansion segment of LSU rDNA (Nadler et al., 2000). PCR cycling parameters included denaturation at $95^{\circ} \mathrm{C}$ for $4 \mathrm{~min}$, followed by 35 cycles of $94^{\circ} \mathrm{C}$ for $30 \mathrm{sec}, 49^{\circ} \mathrm{C}$ for $30 \mathrm{sec}$, and $72{ }^{\circ} \mathrm{C}$ for $70 \mathrm{~s}$.

Several pairs of primers were tested for the amplification of ITS rDNA region of these ascaridids. Stable results were obtained with 

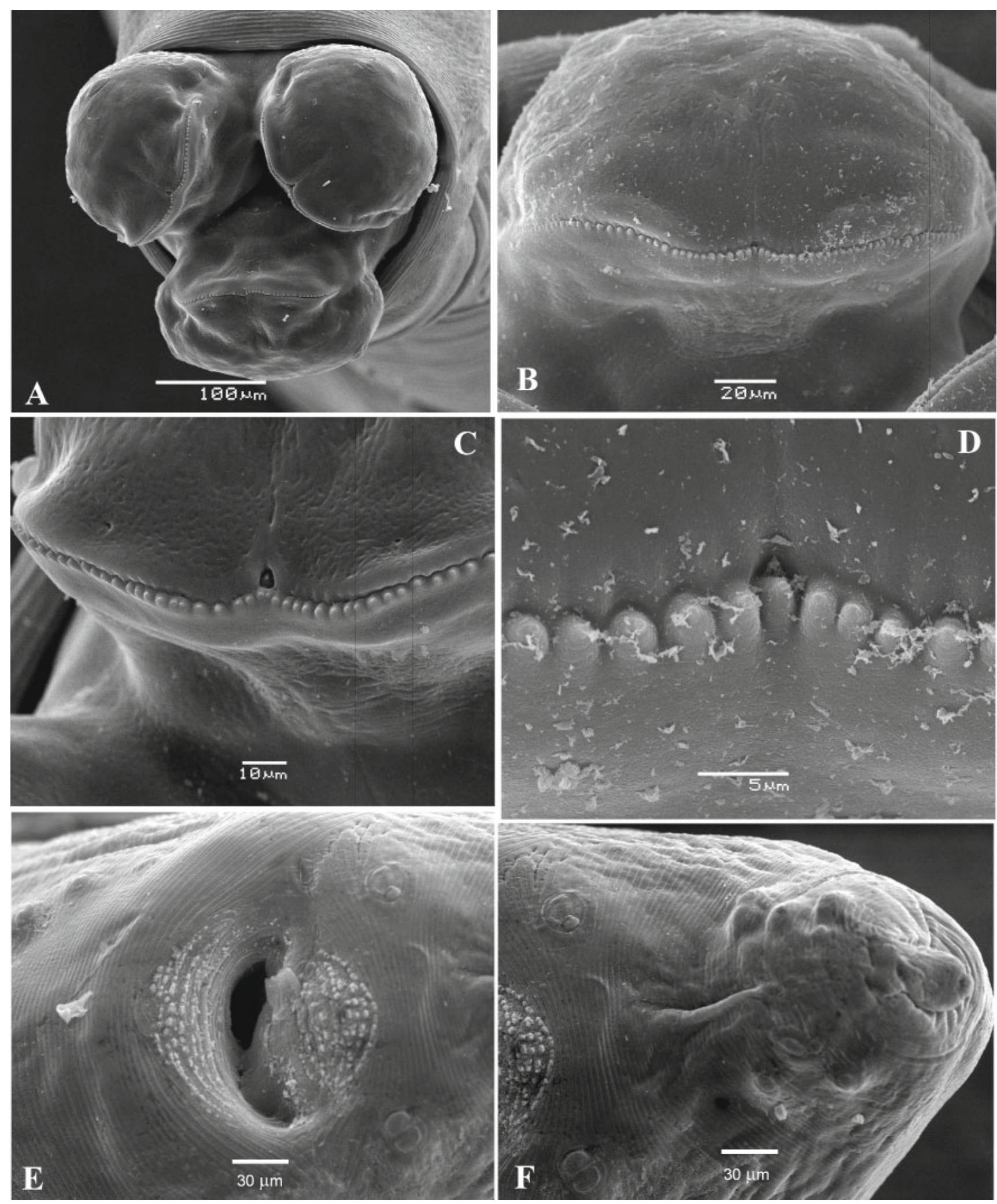

Fig.1. Baylisascaris devosi Sprent, 1952 from Kamchatka sables.

A - apical view of anterior end, female; B C - the row of denticles on the lip, female; D - structure of separate denticles on the lip surface, female; $\mathrm{E}$ - cuticular structures around male cloacal opening; $\mathrm{F}$ - postcloacal papillae near the male tail end. 
the use of the primer pair: Vrain_F (5'- TTG ATT ACG TCC CTG CCC TTT - 3') and AB28 (5'- ATA TGC TTA AGT TCA GCG GGT $\left.3^{\prime}\right)$ proposed before for amplification of diverse groups of nematodes (Vrain et al., 1992; Joyce et al., 1994). PCR cycling parameters included primary denaturation at $94{ }^{\circ} \mathrm{C}$ for 5 min followed by 35 cycles of $94^{\circ} \mathrm{C}$ for $30 \mathrm{~s}, 52^{\circ} \mathrm{C}$ for $35 \mathrm{~s}$ and $72^{\circ} \mathrm{C}$ for $70 \mathrm{~s}$. The obtained $1050 \mathrm{bp}$ long amplicon contained partial $18 \mathrm{~S}$ rDNA, complete ITS1 and 5.8S and partial ITS2 rDNA.

PCR products were visualised in agarose gel and bands were excised for DNA extraction with Wizard SV Gel and PCR CleanUp System (Promega, Madison, USA). Samples were directly sequenced using the same primers as used for primary PCR reactions. The sequences were combined and aligned using the ClustalX program after the addition of sequences from the GenBank (Thompson et al., 1997). Subsequently, the sequences were edited using the Genedoc 2.7 program (Nicholas et al., 1997), to prepare a file for the analysis in MEGA5 (Tamura et al., 2011). Phylogenetic trees were obtained with different methods (MP maximum parsimony, $\mathrm{NJ}$ - neighbour joining and $\mathrm{ML}$ - maximum likelihood) and pairwise nucleotide differences were calculated.
Obtained sequences were deposited in GenBank (KX646394 for the Coxl mtDNA sequence obtained with HCO2198/LC01490 primers and KX682028 for the CoxI mtDNA sequence obtained with JB3_F/JB7GED_R primers; KY465505 for the ITS rDNA sequence (partial 18S, ITS1, 5.8S and partial ITS2 rDNA) and KY465564 for the partial LSU rDNA).

\section{Results}

The examination of the studied Baylisascaris devosi specimens from Ust-Kamchatsky and Milkovsky did not reveal any significant morphological and molecular differences between sites and all the available material was considered as conspecific and homogenous. Baylisascaris devosi was a dominant helminth species in Karaginsky district constituting about $60 \%$ of all intestinal parasites of the sables.

The female body length of Kamchatka $B$. devosi is $126 \pm 2.9$ (78 - 168) $\mathrm{mm}(\mathrm{n}=33)$ and the male body length is $85 \pm 4.4 .6$ (58 140) $\mathrm{mm}(\mathrm{n}=20)$. The anterior end of $B$. devosi is divided into three lips (Fig. 1A), with a stomatal opening situated between lip bases.

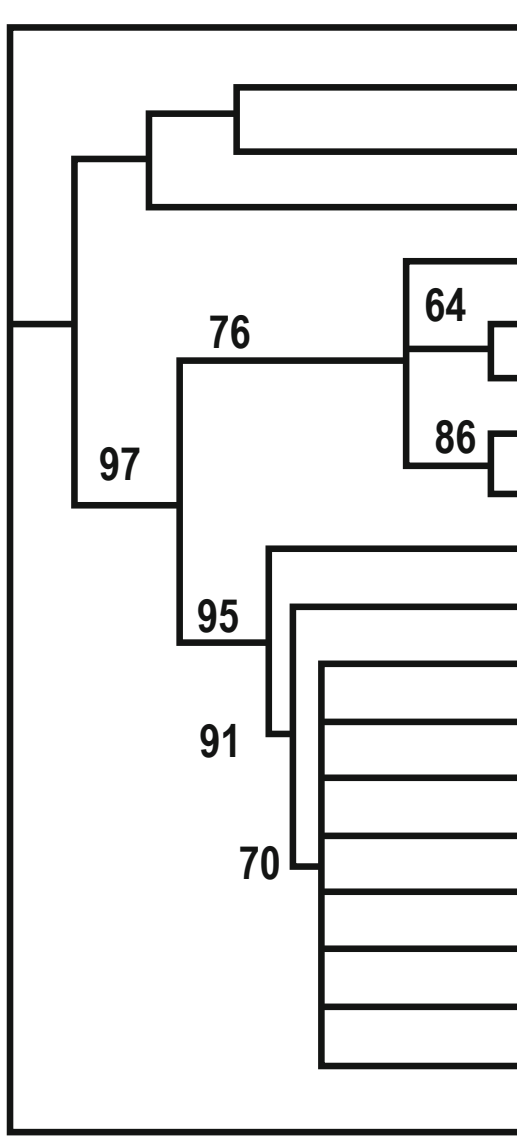

Ascaris suum AB591803

Baylisascaris transfuga HQ671079

Baylisascaris ailuri EU628686

Baylisascaris schroederi EU628682

Baylisascaris columnaris KC543474

Baylisascaris columnaris KC543473

Baylisascaris columnaris KC543472

Baylisascaris procyonis KC172104

Baylisascaris procyonis KC543476

Baylisascaris potosis AB893609

Baylisascaris devosi Kamchatka, Russia

Baylisascaris devosi HapB KM216980

Baylisascaris devosi HapA KM216983

Baylisascaris devosi HapD KM216979

Baylisascaris devosi HapC KM216985

Baylisascaris devosi HapD3 KM216984

Baylisascaris devosi HapD2 KM216982

Baylisascaris devosi HapF KM216981

Baylisascaris devosi HapC KM216978

\section{Toxocara malaysiensis AM412316}

Fig.2. Phylogenetic relationships of Baylisascaris devosi Sprent, 1952 from Kamchatka sables as inferred from analysis of CoxI mtDNA. Maximum parsimony $50 \%$ majority rule consensus tree, 1000 bootstrap replicates, bootstrap values are indicated near nodes; HapA-HapF - different haplotypes of $B$. devosi from Canadian wolverines. 
The lip margins around the vestibulum of the stomatal cavity are armed with the row of denticles (Fig. 1B-D). The denticles on the lip margin have triangular appearance under a light microscope, however under a scanning electron microscope they look rather as rounded elevations of the cuticle with a sharp tip and a wide basal part (Fig. 1D). The posterior end of several B. devosi males showed the presence of spikes on pre- and postcloacal fields (Fig. 1E). Genital papillae are scattered on the subventral part of the body both in pre-cloacal and post-cloacal parts of the male posterior end (Fig. 1F).Total count of pre-cloacal genital papillae was around $48(42-51 ; n=4)$. Five pairs of post-cloacal genital papillae are recognizable under SEM, including doubled first and second pairs. The female reproductive system is characterized by the position of vulvar opening on the border between the first and second quarter of the body length. Vulva position expressed as percentage of body length is $38.8(28.8-51) \%(n=33)$ Egg-shells (length $\mathrm{x}$ width $=68-80 \times 54-62 \mu \mathrm{m}, \mathrm{n}=20$ ) are evenly covered with minuscule pits.

BLAST analysis of CoxI mtDNA sequence of $B$. devosi obtained with primers HCO2198 and LC01490 suggested Baylisascaris procyonis Stefanski \& Zarnowski, 1951 (JF951366) as the most similar species. In the 604 bp long alignment, these species differ in 22 positions. Two other Baylisascaris species with known complete mitochondrial genomes, B. ailuri (Wu, He \& Hu, 1987) (HQ671080) and B. schroederi Mclntosh, 1939 (HQ671081), were more divergent with nucleotide differences in 45 and 46 bp, respectively. The data for more Baylisascaris species are available in NCBI GenBank for another part of Coxl mtDNA (which is closer to 3' end of this gene compared with the fragment amplified with HCO2198 and LCO1490 primers). To obtain such a sequence for Kamchatka's B. devosi, the primers JB3_F and JB7GED_R were used. Though the total length of the obtained sequence was 520 $\mathrm{bp}$, only the $378 \mathrm{bp}$ long alignment of all available sequences was constructed for the shorter length of sequences deposited for several species. Kamchatka Baylisascaris devosi was found forming the strongly supported clade on the phylogenetic tree with several haplotypes of Canadian B. devosi (Nemeth, Tannis, 2014) and occupying basal position in this clade under all methods of analysis (Fig. 2). Both Canadian and Kamchatka's B. devosi sequences grouped together with $B$. potosis into a clade with a moderate to strong support under different methods of analysis. Four Baylisascaris species: $B$. columnaris, $B$. devosi, $B$. potosis and $B$. procyonis were united in the strongly supported clade whilst three remaining species ( $B$. ailuri, $B$. schroederi and $B$. transfuga) with known Coxl mtDNA formed yet another clade (Fig. 2). The pairwise differences in the Coxl mtDNA sequence under comparison displayed the hiatus in the level of intraspecific and interspecific differences. Thus, the difference between numerous studied haplotypes of $B$. schroederi as well as between 8 haplotypes of Canadian $B$. devosi accounted for $1-4 \mathrm{bp}$. The Kamchatka's sample of $B$. devosi differed from Canadian ones in $5-7 \mathrm{bp}$. Apart from the pair ' $B$. ailuri $-B$. transfuga' with the difference in Coxl mtDNA sequences of $11 \mathrm{bp}$, the majority of Baylisascaris species differ in $15-31 \mathrm{bp}$.

The addition of two nuclear loci of Baylisascaris devosi to the analysis supported its close relationships with B. potosis (Fig. 3). In both analyses the nucleotide difference between these two taxa was minimal one between studied Baylisascaris species: 4 bp in ITSrDNA (407 bp long alignment) and 2 bp in LSU rDNA (687 bp long alignment) sequences, correspondingly. An analysis of LSU rDNA demonstrated the well supported relationships between $B$. devosi $+B$. potosis and $B$. procyonis $+B$. columnaris. An analysis of ITS has revealed the strong support for the clade ( $B$. devosi $+B$. potosis) $B$. procyonis). No ITS rDNA sequences for $B$. columnaris are available in NCBI GenBank.

\section{Discussion}

Up to now, the taxonomical identification of the ascaridids of Kamchatka sables was based on morphological features only. Two features, considered as important diagnostic characters (Sprent, 1968) of the genus Baylisascaris were observed: the presence of papilla-like sensory structures on dorsal and subventral lips and two areas (pre- and postcloacal) of the modified cuticle covered with small spikes in males. The traits as the number of papillae in subventral precloacal rows in males, the eggshells with tiny pits, triangular denticles on the lip margins with the base width exceeding its height and anteriorly displaced vulvar opening (situated at $38 \%$ of body length from anterior extremity) also support the identification of these ascaridids from Kamchatka sables as the members of Baylisascaris genus.

This morphologically based identification was supported in our study by the molecular data showed that Canadian Baylisascaris devosi from volverines Gulo gulo L., 1758 were the most similar to the material from Kamchatka in the Coxl mtDNA sequence. It is worth to mention that according to the phylogenetic analysis of partial CoxI mtDNA, $B$. devosi formed the well supported clade with $B$. potosis described from the captive South American kinkajou (Tokiwa et al., 2014). The similarity in nucleotide sequences of three loci was congruent with the morphological similarity of these two species displayed in the similar distribution of postcloacal genital papillae, as well as the shape and number of denticles on the lip margins. This clade of $B$. devosi $+B$.potosis was clustering with two other species of the genus in the well supported clade consisting of $B$. columnaris (Leidy, 1856) from skunks and $B$. procyonis from raccoons. It can be stated that all these species originate mainly from predaceous Musteloidea of the New World. Therefore, it can be assumed that the speciation events for this group of Baylisascaris mainly happened in Americas, and the presence of $B$. devosi in Kamchatka is a result of the later westward expansion. Post-glaciation expansion of Musteloidea in North America might be one of the factors influencing such westward transfer of parasites (Koehler et al., 2009). According to the analysis of three studied DNA loci, three species of Baylisascaris: $B$. ailuri from the 


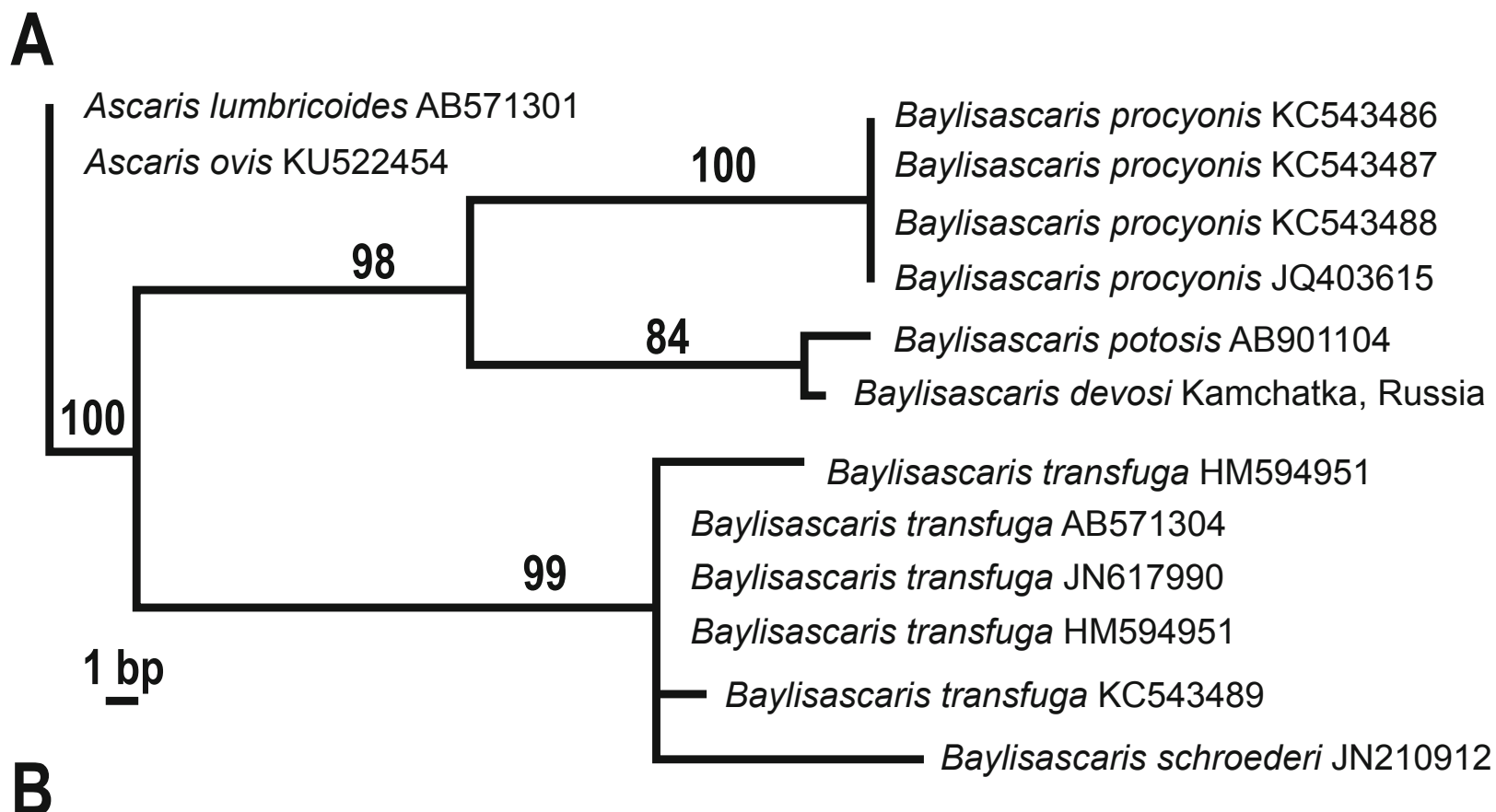

Ascaris suum AY821773

Ascaris lumbricoides AY210806

Parascaris equorum AY821775 Toxascaris leonina U94769

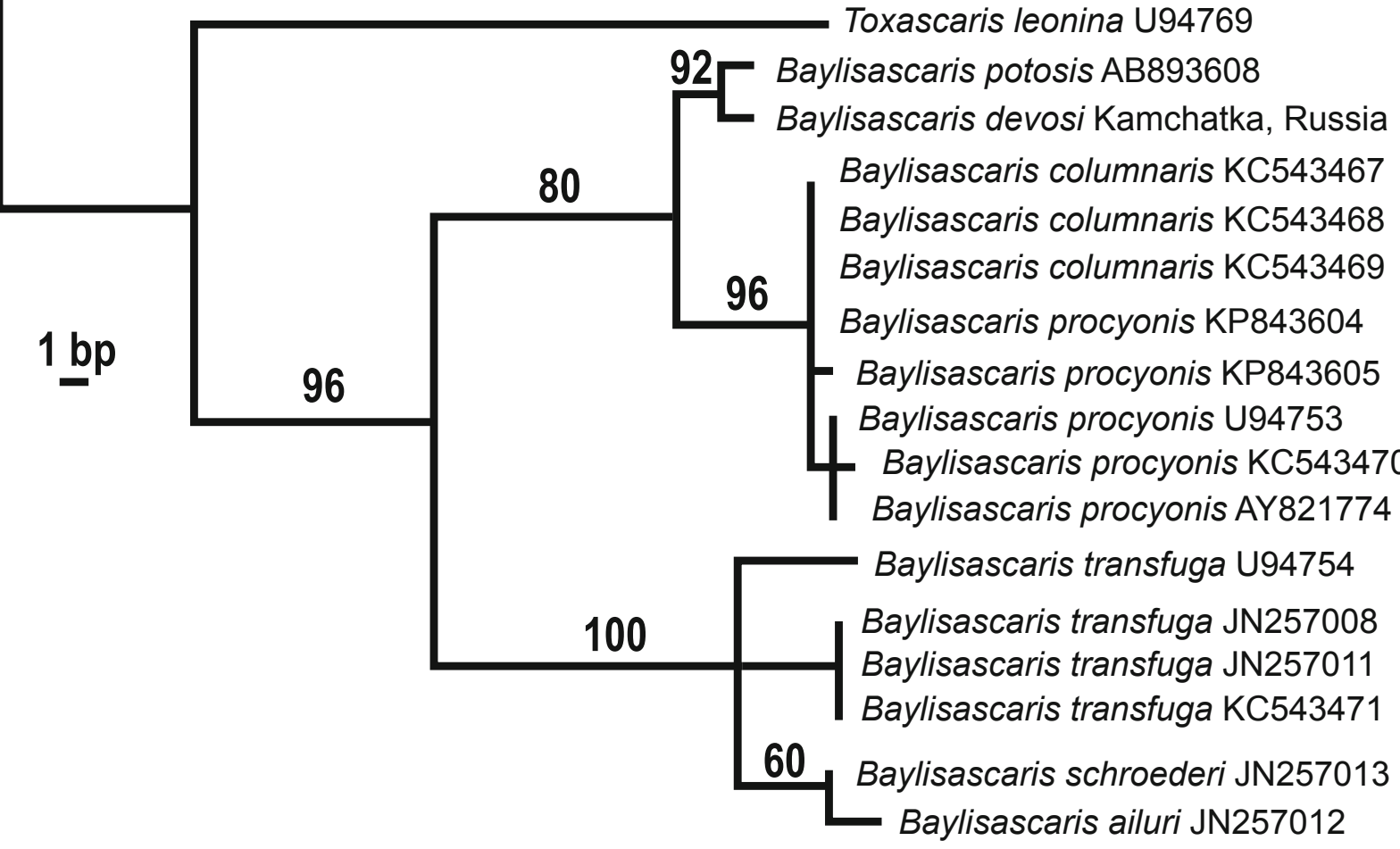

Fig.3. Phylogenetic relationships of Baylisascaris devosi Sprent, 1952 from Kamchatka sables as inferred from analysis of rDNA sequences. Maximum parsimony $50 \%$ majority rule consensus tree, 1000 bootstrap replicates, bootstrap values are indicated near nodes: A - analysis of ITS rDNA (ITS1 + 5.8S + partial ITS2) sequence; B - analysis of partial LSU rDNA sequence (D2D3 expansion segment). 
red panda, $B$. schroederi from the giant panda and $B$. transfuga (Rudolphi, 1819) from the different Ursidae cluster together (Xie et al., 2011). These species are reported mainly from Eurasia and it can be presumed that at least some speciation events happened on Asian mainland.

The average nucleotide difference between Baylisascaris species was on the level of $14-31 \mathrm{bp}$ in the partial Coxl mtDNA (about $4-9 \%$ in the 359 bp long alignment); about $2-18$ bp in LSU rDNA (0.2 - $2.6 \%$ of the $687 \mathrm{bp}$ long alignment) and $4-35 \mathrm{bp}$ in ITS rDNA (1 - $9 \%$ of 407 bp long alignment). The differences between Baylisascaris species and representatives of the Ascaris, Parascaris and Toxascaris genera were about twice bigger, with the exception of Coxl mtDNA alignment, where the difference between Ascaris and Baylisascaris species was on the same level (30 - 36 bp) as interspecific for the latter genus.

Large ascaridids like Baylisascaris are not easy objects for morphological observations, as its thick, dense body prevents the examination of inner structures. Molecular data can serve as a decisive argument in the identification of species. The genus Baylisascaris is also an inviting object for the studies in evolutionary parasitology, as even incomplete phylogenetic data demonstrate the complicated host specialization and geographic expansion of these nematodes. No molecular data are yet available for two species with deviant biology: $B$. tasmaniensis from marsupials and $B$. laevis from rodents. Together with the $B$. melis from badgers these three species await molecular studies to be used in the analysis of sequence data. The level of DNA polymorphism in the most widespread species of Baylisascaris is yet another important direction of study. E.g., the reported intraspecific variability in B. transfuga from bears is exceeding some interspecific differences within the genus and it will be both interesting and helpful for the genus taxonomy to estimate the level of nucleotide differences between populations from different areas and hosts.

\section{Acknowledgment}

We are grateful to anonymous reviewer for valuable comments and the linguistic improvement of the paper.

\section{References}

Bowles, J., BlaiR, D., McManus, D.P. (1992): Genetic variants within the genus Echinococcus identified by mitochondrial DNA sequencing. Mol. Biochem. Parasitol., 54(2): 165-174

Derycke, S., Vanaverbeke, J., Rigaux, A., Backeljau, T., Moens, T. (2010): Exploring the Use of Cytochrome Oxidase c Subunit 1 (COI) for DNA Barcoding of Free-Living Marine Nematodes. PLoS One, 5(10): (e13716), p. 1 - 9. DOI: 10.1371/journal.pone.0013716 Folmer, O., Black, M., Hoeh, W., Lutz, R., VRiJenhoek R. (1994): DNA primers for amplification of mitochondrial cytochrome $\mathrm{C}$ oxidase subunit I from diverse metazoan invertebrates. Mol. Mar. Biol. Biotechnol., 3(5): $294-299$
Joyce, S.A., Reid, A., Driver, F., Curran, J. (1994): Application of polymerase chain reaction (PCR) methods to the identification of entomopathogenic nematodes. In: BuRnelL, A.M., EHLERS, R.-U., MASSON, J.-P. (Eds). COST 812 Biotechnology: Genetics of entomopathogenic nematodes-bacterium complexes. Proceedings of symposium and workshop, St Patrick's College, Maynooth, County Kildare, Ireland. Luxembourg, European Commission, DGXII, pp. $178-187$

Holterman, M., Van der Wurff, A., Van den Elsen, S., Van Megen, H., Bongers, T., Holovachov, O., Bakker, J., Helder, J. (2006): Phylum-wide analysis of SSU rDNA reveals deep phylogenetic relationships among nematodes and accelerated evolution towards crown clades. Mol. Biol. Evol., 23: 1792 - 1800. DOI: 10.1093/ molbev/msI044

Koehler A.V.A., Hoberg, E.P., Dokuchaev, N.E., Tranbenkova, N.A., Whitman, J.S., Nagorsen, D.W., Cook, J.A. (2009): Phylogeography of a Holarctic nematode, Soboliphyme baturini, among mustelids: climate change, episodic colonization, and diversification in a complex host-parasite system. Biological Journal of the Linnean Society, 96(3): 651-663. DOI: 10.1111/j.1095-8312.2008.01145.x KontRImAVICHUS, V.L. (1963): The helminthes of the Mustellidae of the Far East. Trudy Gelminthologicheskoy laboratorii Academii Nauk SSSR, 11: $26-47$

KonTRIMAVICHUS, V.L. (1966): Helminth fauna of USSR martens (Mustellidae). Trudy Gelminthologicheskoy laboratorii Academii Nauk SSSR, 17: 54 - 82

KontRIMAVICHUS, V.L. (1969): Helminth fauna of mustellids and the pathways of its formation. Moscow, Nauka Publishing House, 432 pp.

KontrimaVichus, V.L., SkRJabina, E.S. (1963): The helminthes of sable and ermine of Kamchatka. Trudy Gelminthologicheskoy laboratorii Academii Nauk SSSR, 13: 48 - 51

Kozlov, D.P. (1977): Identification keys for helminthes of predaceous mammals of the USSR fauna. Moscow, Nauka Publishing House, $275 \mathrm{pp}$.

Mozgovoy, A.A., Shakhmatova, V.I. (1973): Ascaridata of animals and man and the diseases caused by these parasites. Foundations of nematology, Volume $23\left(2^{\text {nd }}\right.$ part). Moscow, USSR: Nauka Publishing House. $247 \mathrm{pp}$.

Nadler, S.A., D’Amelio, S., Fagerholm, H.-P., Berland, B., Paggi, L. (2000): Phylogenetic relationships among species of Contracaecum Railliet \& Henry, 1912 and Phocascaris Høst, 1932 (Nematoda: Ascaridoidea) based on nuclear rDNA sequence data. Parasitology, 121 (4): $455-463$

Nemeth, C., Tannis, M. (2014): In: Wacky Work on Worms in Wolverines. The identification of Baylisascaris devosi parasite. Retrieved May 2016 from http://words.usask.ca/wcvm/ files/2014/07/ wolverine-research-poster.pdf

Nicholas, K.B., Nicholas, H.B. JR., Deerfield, D.W. (1997): Multiple Sequence Alignment Editor and Shading Utility, Version 2.7.000. http://www.psc.edu/biomed/genedoc

Pérez A.M., Pérez H.K., Parra J.G. (2016): Morphological and mo- 
lecular description of Baylisascaris venezuelensis n. sp., from a natural infection in the South American spectacled bear Tremarctos ornatus Cuvier, 1825 in Venezuela. Neotropical Helminthology, 10(1): 85 - 103

Petrow, A.M. (1930). Zur Characteristic des Nematodes aus Kamtchatken Zobelen Soboliphyme baturini nov. gen., nov. sp. Zoologischer Anzeiger 86 (9-10): 265 - 271

SPRENT, J.F.A. (1952): On an Ascaris of the fisher and marten, Ascaris devosi sp. nov. Proc. Helminthol. Soc. Wash., 19(1): 27 - 37 SPRENT J.F.A. (1953): On the life history of Ascaris devosi and its development in the white mouse and the domestic ferret. Parasitology, 42(3/4): $244-258$

SPRENT, J. F. A. (1968): Notes on Ascaris and Toxascaris, with a definition of Baylisascaris gen. nov. J. Parasitol., 58(1): 185 - 198 SPRENT, J.F.A. (1970). Baylisascaris tasmaniensis sp. nov. in marsupial carnivores: heirloom or souvenir? Parasitology, 61(1): 75 - 86 Tamura, K., Peterson, D., Peterson, N., Stecher, G., Nei, M., KuMAR, S. (2011): MEGA5: Molecular evolutionary genetic analysis using maximum likelihood, evolutionary distance, and maximum parsimony methods. Mol. Biol. Evol., 28(10): 2731 - 2739. DOl: 10.1093/molbev/msr121.
Tokiwa, T., Nakamura, S., TalRa, K., Une, Y. (2014): Baylisascaris potosis n. sp., a new ascaridid nematode isolated from captive kinkajou, Potos flavus, from the Cooperative Republic of Guyana. Parasitol. Int. 63(4): 591 - 596. DOI: 10.1016/j.parint.2014.03.003. TranBenKova, N.A. (1987): The helminth fauna of Kamchatka predatory mammals and its peculiarities // In Abstracts XVIII-th Congress of the International Union of Game Biologists,). Kraków, Poland: Jagellonian University, Krakow, 1987, pp. 204 - 205

WILKIE, J.S. (1930): Note on occurrence of Ascaris columnaris Leidy in Siberian Mustellidae. Ann. Mag. nat. Hist. 10th Series, 6: $65-67$

Vrain, T.C., Wakarchuk, D.A., LeVesque, A.C., Hamilton, R.J. (1992). Intraspecific rDNA restriction fragment length polymorphism in the Xiphinema americanum group. Fund. Appl. Nematol. 15(6), 563 $-573$

Xie, Y., Zhang, Z., Wang, C., Lan, J., Li, Y., Chen, Z., Fu, Y., Nie, H., Yan, N., Gu, X., Wang, S., Peng, X., Yang, G. (2011): Complete mitochondrial genomes of Baylisascaris schroederi, Baylisascaris ailuri from red panda and Baylisascaris transfuga from giant pan$\mathrm{da}$, red panda and polar bear. Gene 482(1 - 2): 59 - 67. DOI: 10.1016/j.gene.2011.05.004 